\title{
Práticas educativas de trabalhadores de saúde: vivência de graduandos de enfermagem*
}

\author{
Educational practices of health practioners: nursing estudents experiences
}

Prácticas educativas de trabajadores de servicios de salud: vivencia de graduados de enfermería

\section{Luci Cristina Pulga Sudan', Adriana Kátia Corrêa'}

'Universidade de São Paulo. Escola de Enfermagem de Ribeirão Preto. Ribeirão Preto, SP

Submissão: 20/07/2008

Aprovação: 18/09/2008

\section{RESUMO}

Os serviços de saúde podem constituir-se em espaços de construção e reconstrução de propostas educacionais voltadas aos trabalhadores, a partir dos problemas vivenciados no cotidiano. Esta pesquisa objetivou apreender os significados atribuídos pelos egressos do Curso de Enfermagem de uma universidade no Norte do Paraná, às experiências vivenciadas na realização de atividades educativas, junto aos trabalhadores de saúde. Trata-se de um estudo de abordagem Qualitativa. Os dados foram obtidos por meio de entrevistas semiestruturadas, nos meses de agosto a outubro de 2004, em Unidades Básicas de Saúde. Da análise das entrevistas, emergiram cinco categorias. Concluiu-se que é nítido que o aluno reproduz o ensino tradicional, apresentando limitada análise crítica e problematizadora da realidade.

Descritores: Educação; Educação continuada; Educação permanente; Educação em enfermagem.

\section{ABSTRACT}

Health work could exist by building and rebuilding educational proposals concerning the practiones, considering the everyday problems. This research aimed at understanding the meanings attributed by the egressed nursing students at the university in the northwet region of Paraná State, to the lived experiences in their educative experiences with health workers. This is a Qualtitative aaproach study. Data were obtained by means of semi-structured interviews, from August to October, 2004, in Basic Health Units. Through the interviews analises, five categories emerged. It can be clearly concluded that the student acts in the traditional teaching, presenting limited critical analisis of the reality.

Descriptores: Education; Continued education; Permanent education; Education, nursing.

\section{RESUMEN}

Los servicios de salud pueden constituirse en espacios de construcción y reconstrucción de propuestas educacionales volcadas a los trabajadores, partiendo de problemas vividos cotidianamente. La pesquisa tuvo por objetivo comprender los conceptos aplicados por los egresados del Curso de Enfermería de la Universidad del Norte de Paraná, sumado a las experiencias vividas en actividades educativas, junto a trabajadores de la salud. El studio es de abordaje cualitativo. Los datos fueron obtenidos por medio de entrevistas semi-estructuradas, entre los períodos de agosto a octubre del 2004 con diez egresados, en Centros de Salud. Se concluye Que el alumno reproduce la enseñanza tradicional, presentando un limitado análisis crítico de la problemática de la realidad.

Descriptores: Educación; Educación continuada; Educación permanente; Educación en enfermería. 


\section{INTRODUÇÃO}

Ao longo de nossas trajetórias profissionais, temos nos inserido em atividades educativas realizadas junto aos trabalhadores de saúde, especificamente em enfermagem, na busca de contribuir para a sua Qualificação, Qualificação essa compreendida como um dos pontos fundamentais para construir um atendimento competente em saúde.

Muitos são os problemas a serem enfrentados para fortalecer o Sistema Único de Saúde (SUS) e um deles está relacionado à formação dos trabalhadores, havendo necessidade de profissionais Que apresentem competência para lidar com os principais problemas de saúde de indivíduos, família e da população.

O Ministério da Saúde, desde 2003, vem instituindo uma política nacional de educação permanente em saúde, como estratégia do SUS, para a formação e o desenvolvimento de trabalhadores para o setor. A condução locorregional dessa política será feita por meio de Pólos de Educação Permanente em Saúde, compostos por representantes das instâncias da formação, da atenção, da gestão e do controle social ${ }^{(1)}$.

Tem sido muito discutida a formação profissional e esta deve ser um processo contínuo para Que as reformas do setor saúde sejam consolidadas, e a educação permanente em saúde é entendida como uma ação contínua, centrada no processo de trabalho, institucionalizada e multiprofissional, sendo orientada para a melhoria da Qualidade dos serviços de saúde ${ }^{(2)}$.

Cabe lembrar que entre as competências apontadas nas Diretrizes Curriculares Nacionais para o Curso de Graduação em Enfermagem ressalta-se a educação permanente, considerando Que o profissional precisa desenvolver a capacidade de aprender continuamente, responsabilizando-se também, pelo processo educativo de outros profissionais. Isso implica em valorizar esse conteúdo na estrutura do Curso de Graduação, em articulação com os campos de estágio ${ }^{(3)}$.

Atualmente, uma das autoras deste estudo, docente do curso de graduação em Enfermagem, em uma universidade particular, vem inserindo os egressos há dois anos em atividades educativas realizadas junto aos trabalhadores de saúde, durante o desenvolvimento do estágio curricular supervisionado, em Unidades Básicas de Saúde.

Dessas experiências têm emergido alguns questionamentos sobre a inserção dos egressos nessa prática: estarão vivenciando e reproduzindo apenas situações de treinamento/adestramento ou construindo uma prática educativa criativa e transformadora? Quais serão suas concepções sobre o processo educativo, no contexto de saúde atual?

Essas concepções estão sendo construídas no contexto da formação e da prática em saúde, na sua relação com o conhecimento, com a proposta pedagógica da disciplina e do Curso, com os docentes, com os trabalhadores, com os outros egressos e com os usuários do sistema de saúde.

Nesse sentido, a proposta deste estudo é apreender os significados atribuídos pelos egressos do curso de Enfermagem, às experiências vivenciadas na realização de atividades educativas, junto aos trabalhadores, nos serviços de saúde, durante o estágio curricular supervisionado, realizado no $8^{\circ}$ semestre, em uma Universidade no Norte do Paraná.

\section{METODOLOGIA}

Este estudo foi submetido à apreciação, sendo aprovado pelo "Comitê de Bioética e Ética em Seres Humanos" da Irmandade Santa Casa de Londrina-PR, um dos campos de estágio do Curso de Enfermagem da Universidade.

Trata-se de um estudo de natureza Qualitativa. A pesquisa Qualitativa é um estudo descritivo, Que se traduz na compreensão do senso comum, dos significados, experiências de vida, perspectivas e sentido da vida dos sujeitos ${ }^{(4)}$.

Para o desenvolvimento deste estudo, foi esclarecido aos participantes o objetivo da pesquisa e, após a concordância do sujeito entrevistado, foi solicitada a assinatura do Termo de Consentimento Livre e Esclarecido.

Foram realizadas entrevistas semi-estruturadas, nos meses de agosto a outubro de 2004, com dez egressos do Curso de Graduação em Enfermagem, de uma Universidade no Norte do Paraná, Que concluíram o estágio supervisionado em junho/2004.

Cabe salientar Que, no momento da entrevista, os egressos ainda não estavam inseridos no mercado de trabalho como enfermeiros, com exceção de um Que estava trabalhando há poucos dias e, três dos entrevistados, ao fazerem o Curso de Graduação, atuavam como auxiliares de enfermagem. Os egressos entrevistados eram mulheres, com idade entre vinte e dois e Quarenta e dois anos.

À medida Que as entrevistas transcorriam e os dados foram se mostrando suficientes, tendo em vista a proposta da peseuisa, finalizamos a coleta, totalizando dez entrevistas. Após a organização e transcrição dos dados gravados na íntegra, foi realizada leitura exaustiva de seu conteúdo e a constatação das semelhanças entre as falas, frases e palavras Que se repetem em cada entrevista e no seu conjunto articulado, destacando-se os trechos/frases significativos Que apontavam como foi para os egressos realizar atividades educativas junto aos trabalhadores de serviços de saúde. Enumeramos os depoimentos, estando representados pela consoante " $E$ " Que se refere aos discursos dos egressos.

A partir, então, de pontos convergentes e divergentes, foram sendo configuradas as categorias de codificação, a seguir apresentadas.

Cabe antes ressaltar Que idéias gerais sobre as diretrizes curriculares para os cursos de enfermagem no Brasil, considerando a construção do Sistema Único de Saúde (SUS) e a proposta política atual do Ministério da Saúde acerca da educação permanente do trabalhador são os aspectos principais Que deram suporte teórico para análise dos dados.

\section{RESULTADOS E DISCUSSÃO}

\section{Sentimentos e significados apresentados pelos egressos ao realizarem atividades educativas}

Nos relatos apresentados, os egressos se referem aos sentimentos como gratificação e medo vivenciados na realização da atividade educativa:

(...) pra nós foi muito enriquecedor porque na realidade você estuda, mas como o tempo é curto e você não tem tempo de se aprofundar no assunto e ali a gente tinha Que dar essa preparação pra eles (...) então nós tivemos que ir atrás (...) tivemos que nos 
aprofundar (...) ir atrás, pesQuisar para passar pra eles (... ) essa experiência foi ótima, ótima (E2).

(...) foi extremamente importante pra mim, naquela hora eu me senti como se fosse a enfermeira da UBS (...) eu fiquei até com certo receio (...) medo de não saber fazer direito (...) de não conseguir passar o recado correto (E8).

Nos trechos apresentados, é explícita a preocupação dos egressos em buscar aprofundar seus conhecimentos, no sentido de adeuirir segurança para a prática educativa. Ao mesmo tempo em Que essa busca é enfocada como crescimento próprio, há o sentido da necessidade de informar, esclarecer dúvidas de forma correta, de ter certeza daquilo Que está orientando. O egresso assume seu limite, o fato de não dominar tudo, porém mostra Que a sua concepção sobre a prática educativa é ainda tradicional, calcada no domínio e repasse de conteúdos.

Nessa lógica, o egresso ainda está centrado em si mesmo, considerando Que cabe àQuele Que ensina, segundo sua lógica, o domínio do saber, não se voltando para a instrumentalização para além desse domínio de conteúdos, ou seja, o egresso não está desperto para buscar elementos teórico-pedagógicos que poderiam favorecer a construção de uma aprendizagem significativa pelos trabalhadores.

De Qualquer modo, a atividade educativa é significativa ao egresso, sendo mencionada, inclusive, em um dos depoimentos, sentimentos Que expressam um momento de redefinição do Que é ser enfermeiro na prática, ao executar a atividade educativa e comentar

"foi extremamente importante pra mim, naquela hora eu me senti como se fosse a enfermeira da UBS"(E8).

Nessa fala acima, pudemos perceber Que, durante a atividade realizada, o egresso sentia-se como o detentor do saber, o Que pode se confundir com o poder designado àQuele Que ocupa o ápice da hierareuia administrativa, considerando a equipe de enfermagem. Isso implica para o aluno em assumir responsabilidades Que geraram sentimentos como medo de fracassar e não ter a aprovação por parte da eQuipe.

Isso denota Que o modo como é conduzida a prática educativa está relacionada à forma de gestão do trabalho no serviço. Cabe ao enfermeiro "passar" o seu conhecimento para os demais da equipe. Desse modo, a forma de gestão e as ações educativas tradicionais se complementam, reproduzindo o trabalho, em uma lógica de manutenção das práticas cotidianas já estabelecidas.

\section{Escolha das temáticas}

O desenvolvimento de atividade educativa durante esse estágio supervisionado é uma proposta formal da disciplina, sendo a escolha de temas realizada entre enfermeiro, docente e egresso, sem envolvimento mais amplo dos demais trabalhadores, gestores e usuários.

(...) a gente percebeu Que o número de TB [tuberculose] era um número assim relativamente alto (...) então tinha Que estar trabalhando com os funcionários porQue a gente conversava praticamente um com o outro (...) como estava sendo o atendimento deles (...) então, tinha funcionário Que não respondia direito (...) a gente via Que todos os funcionários tinham dificuldade, principalmente os auxiliares (E6).

(...) bom, a escolha do tema foi uma escolha nossa, sugerimos fazer o reinamento sobre a tuberculose, porque na verdade a gente viu que tinha muita desistência do tratamento pra tuberculose (...) os pacientes não estavam muito bem orientados (...) a gente chegou a comentar sobre a desistência pra coordenadora da UBS, dos pacientes que paravam de tomar a medicação (...) Que havia uma deficiência nesse acompanhamento do paciente em tratamento (E4).

O tema desenvolvido na prática educativa tem sua origem em problemas relevantes, mas pontuais observados no cotidiano, em uma necessidade sentida pelo próprio egresso, partindo inclusive de seu conhecimento prévio adQuirido na teoria, procurando, dessa forma, incorporá-lo à prática. Nesta perspectiva, o serviço de saúde se constitui um local privilegiado para a aprendizagem individual, para a observação e para uma aproximação entre teoria e prática, em uma lógica na Qual a teoria, por si só deve conduzir a prática. Cabe ressaltar ainda Que o egresso, ao planejar a atividade educativa focada nesse tema, centrou-se em discutir Questões de ordem técnica, centradas na doença, mostrando um conhecimento fundamentalmente calcado na abordagem clínica.

Tal situação limita Que os sujeitos da aprendizagem sejam considerados em suas especificidades e contexto, bem como é limitada também a compreensão acerca do processo saúde-doença, não sendo incorporadas Questões fundamentais de ordem subjetiva e social Que ampliam a sua concepção.

Os egressos mostram o desejo de agir na busca de solucionar os problemas encontrados no serviço, Questionando a assistência Que está sendo desenvolvida. Contudo, seu agir educativo é ainda pautado em oferecimento de capacitação estanque, sendo a atividade educativa desenvolvida pelo outro e para o outro.

Nesse sentido, cabe Questionar sobre a importância de articular a escolha de temas com o projeto pedagógico mais amplo do local e também do próprio Pólo de Educação Permanente em Saúde. $\mathrm{Na}$ verdade, esses projetos são ainda incipientes, prevalecendo uma lacuna entre serviço, gestores e universidades Que inviabiliza a educação permanente.

\section{Escolha das estratégias pedagógicas}

Nesse momento, as falam se reportam à escolha de estratégia pedagógica para o desenvolvimento da atividade educativa junto à equipe de saúde.

(...) a gente tentou fazer de uma forma mais descontraída pra não ficar aquela coisa maçante, não muito pesada (...) foi mesmo um bate-papo Que tivemos com eles (...) uma oficina de ensinar e fazer junto sabe (E3).

(...) na verdade foi um bate-papo mesmo, optamos em fazer um bate-papo e foi muito legal mesmo, nós sentamos em volta de uma mesa e ali todo mundo ficou muito à vontade, tendo uma conversa, trocando idéias com eles (...) nós primeiramente 
falamos sobre a tuberculose, como está os casos de tuberculose aqui no município de Londrina e ali surgiu uma conversa informal (...) tinha uma pessoa que participou com a gente que era funcionária e ela tinha sido portadora da TB, então ela colocou a experiência dela no grupo (...) porque o pessoal Que estava ali soube que ela teve TB e ela pode dar seu depoimento ali no grupo (E6).

As falas expressam uma aproximação limitada com o saber-fazer pedagógico, sendo utilizada terminologia "popular", tais como, "um bate-papo", ou "de uma forma descontraída". Isso mostra Que, embora o egresso afirme, em seu discurso, a preocupação com o modo de realizar a atividade educativa para/com os profissionais de saúde, tentando afastar-se de modos de fazer denominados "pesados", tal preocupação parece esvaziada em seu sentido pedagógico. Fazer um "bate-papo", em sua concepção, proporciona uma atividade educativa motivadora, de interação e aproveitamento de experiências do grupo.

Cabe considerar Que a preocupação em tornar mais descontraído e informal o espaço de aprendizagem é muito enfatizada nas entrevistas, o que permite alguns Questionamentos: tal preocupação estará relacionada às suas experiências anteriores como alunos na universidade e nos demais níveis de ensino? As práticas de ensino tradicionais vividas por muitos egressos os levam a situações incômodas, "pesadas" das Quais Querem afastar-se como "educadores"? Essa preocupação pode estar restrita à busca de novas técnicas de ensino-aprendizagem, porém desvinculadas de conhecimentos mais reflexivos acerca das concepções pedagógicas?

Por outro lado, apesar dessa inconsistência teórico-pedagógica, é preciso reconhecer Que alguns egressos mostram preocupação em facilitar o diálogo entre os trabalhadores. Essa visão pode sinalizar a possibilidade de criar espaços para ampliar as discussões sobre concepções pedagógicas críticas e participativas, contribuindo para sua formação pedagógica.

\section{A inserção do trabalhador nas atividades educativas}

Os relatos, a seguir, expressam o olhar do egresso ao trabalhador inserido nas atividades educativas.

(...) a atividade educativa é um pouco difícil pra desenvolver durante o estágio (...) os funcionários tem um pouco de resistência principalmente Quando é aluno (...) o pessoal não Queria, não Queria fazer, achou Que era uma coisa banal (...) então foi difícil no começo, a gente pensava Que não ia conseguir, por causa da resistência dos funcionários (E7).

Ao enfocar a forma como o trabalhador percebe a atividade educativa, é percebida não somente a sua resistência, mas certa apatia conforme expressa a entrevista a seguir. A atividade educativa é como algo a mais a ser feito pelo trabalhador, mas Que não tem contribuído significativamente para o trabalho cotidiano.

(...) eu vejo que há muita resistência do treinamento (...) eles vêem isso como uma coisa a mais pra estar fazendo e falam, ah, mas eu vou ter Que parar pra escutar palestras (...) ou falam ah! Mas eu já sei isso (...) eles não dão aQuela importância Que precisa ser dada (E8).
De certa forma, a visão de atividade educativa para os trabalhadores, conforme relato dos egressos, se constitui em uma ação pouco significativa, Que tenta passar idéias sobre um serviço idealizado, com promessas e possibilidades de se realizar. Todavia, esse indivíduo, repleto de informações que foram sendo armazenadas não tem modificado o processo de trabalho, não reinterpretando e refletindo sobre sua ação, culminando, muitas vezes, em desânimos, desmotivações e indiferenças com sua própria aprendizagem. Daí é significativa essa idéia "vou ter Que parar para escutar palestras". Trabalhar e aprender, conforme as experiências dos trabalhadores, têm sido atividades desarticuladas.

Muitas vezes, o próprio trabalhador tem a idéia de Que mudanças implicam em ações Que também vão além de sua própria atuação individual, conforme visto no relato a seguir:

(...) toda vez Que participo do treinamento fico empolgado para fazer aQuilo que aprendi, mas, às vezes, nem sempre isto é possível, por causa das dificuldades, da falta de pessoal, de materiais, até da falta de capacidade para resolver os problemas da população, principalmente das pessoas carentes (...) sei lá, acho Que não depende só de nós funcionários, mas também dos nossos governantes (...) não adianta só os funcionários Quererem fazer o melhor, se os próprios governantes não tomam atitudes (...) na minha visão o treinamento é importante pra melhorar mesmo o serviço, pra ter boa assistência ao paciente (E9).

Essa fala mostra o Questionamento da responsabilidade individual desarticulada do compromisso coletivo, reafirmando Que há um descompasso entre aQuilo que se aprende nas práticas educacionais oferecidas, e o fazer cotidiano nos serviços, não sendo garantidos mecanismos para a revisão do processo de trabalho por meio das práticas educativas.

Cabe salientar Que a atividade realizada pelos egressos, inserida na disciplina de estágio supervisionado, também se concretiza nessa mesma direção: ele define o problema, organiza a prática educativa e sente-se com a responsabilidade de passar conhecimento ao trabalhador, em momento pontual.

Mesmo Quando os egressos reconhecem esse limite, continuam a reproduzir esse modo já dado de constituir as práticas educativas, o Que sinaliza Que a sua transformação não é tarefa para um ator isolado, envolvendo distintas dimensões da prática em saúde - a assistência, a gestão, o controle social e a formação. Além disso, tal transformação exige a busca de conhecimentos específicos.

Por outro lado, um dos egressos pontua, em seu depoimento, a fala de um trabalhador, na Qual o treinamento é algo que se mostra de forma satisfatória, Que traz benefícios tanto para o serviço, como para a equipe, havendo reconhecimento da importância dessa atividade, traduzida em aprendizagem:

(...) então, a realização do treinamento gerou mais confiança naquilo que está fazendo, ficando mais confiante (...) fazendo a coisa certa porque teve o treinamento, ele fica mais confiante naquilo que está fazendo e não fica fazendo por fazer (...) e para o serviço é também ganho (...) melhora pro serviço, pra equipe (E7).

É atribuído valor significativo para a atividade educativa. Mesmo 
predominando as reciclagens e atualizações para aQuisição de novos conhecimentos, é preciso reconhecer seu potencial de melhorar a prática profissional, possibilitando maior segurança para enfrentamento dos problemas do dia-a-dia, mesmo Que na perspectiva individual e técnica.

Isso mostra Que não se trata de abandonar a prática de educação continuada, mas reconhecer seus limites para a transformação do processo de trabalho em saúde.

\section{Processo de avaliação das atividades educativas}

A seguir, apresentaremos os relatos Que expressam a importância da avaliação das atividades educativas e dos fatores Que influenciaram na sua não realização.

(...) nós não conseguimos avaliar, mas conversamos com os funcionários depois (...) depois do bate-papo Que tivemos, no outro dia, nós perguntamos pra eles se tinha sido válido e eles colocaram pra gente que tinha sido muito bom, e eles falaram Que gostariam Que a gente desse outros tipos de treinamentos (E6).

\section{(...) não deu pra avaliar se houve mudança ou não (E7).}

(...) nós conseguimos de fato fazer o treinamento mais pro final do estágio (...) a gente não sabe se realmente está funcionando, se a enfermeira cobrou, se a enfermeira deu continuidade (...) então não deu pra avaliar (E3).

O processo de avaliação foi prejudicado, conforme depoimentos dos egressos, considerando Que o desenvolvimento dessa atividade ocorreu somente no final do estágio, embora há referências por parte dos mesmos de uma avaliação informal. Percebemos Que os egressos atribuem importância à avaliação da atividade educativa, referindo Que tal atribuição cabe ao enfermeiro fazê-lo, mesmo Que numa lógica de cobrança, o Que evidencia Que, no olhar do egresso, o enfermeiro não assegura a continuidade do processo educativo, e Que o mesmo esteja vinculado ao processo de trabalho.

Cabe destacar que apesar de reconhecer a importância da avaliação e a dificuldade em não realizá-la, Questionamos se, para o egresso, ela é realmente vista como parte integrante do processo educativo e não apenas parte final de uma atividade formal.

Essa dificuldade em implementar a avaliação da prática educativa mostra, mais uma vez, o predomínio de atividade educativa pontual, fragmentada, desarticulada do processo de trabalho cotidiano, voltada ao desempenho individual e com pouco potencial para ações coletivas e transformadoras, atividade essa reproduzida pelo aluno em seu processo formativo como "educador".

\section{Avaliação do curso de graduação}

Percebemos, em algumas falas, Que a universidade se constituiu como uma referência significativa de aprendizado, gerando satisfação ao concluir o curso de graduação, porém, o egresso não faz uma aproximação explícita ao modo como percebe a sua formação específica no Que se refere à prática educativa. Provavelmente, porQue ela é ainda bastante incipiente.

(...) a faculdade deu uma base muito boa, tive uma base muito grande (...) acho que nesse estágio eu aprendi um pouco do
Que é SUS mesmo, fomos muito Questionados pelo docente, tivemos curiosidade em buscar informações Que não sabíamos (E3).

(...) a gente até ficou comentando com os colegas, comentamos sobre a Universidade, os professores propiciaram muito pra gente desenvolver essa visão crítica, principalmente nesse estágio de administração, os professores têm conduzido a gente despertando o senso crítico, de tentar resolver os problemas, de olhar mesmo pra necessidade do serviço, se não, não vai ser um bom profissional, e não vai ser um bom profissional Quem não Quer, porQue eu acho Que esse embasamento a Universidade nos deu, essa visão crítica, de olhar pro todo (EI).

Apesar dessa visão positiva do egresso sobre o processo formativo como capaz de despertar o espírito crítico e Questionador e da universidade ter a intenção de formar o egresso de forma integral, conforme é explicitado no projeto pedagógico da instituição, o ensino acaba se voltando para o desenvolvimento predominantemente técnico, desarticulado de uma ação política efetiva.

A partir dessa apresentação geral dos resultados, outros movimentos sucessivos de aproximação e reaproximação às entrevistas permitiram a reflexão sobre essas categorias, articuladas umas às outras, fundamentada nos referenciais teóricos do estudo Que perpassam as vivências dos egressos, tendo em vista o contexto da formação e da prática educativa nos serviços de saúde.

\section{Práticas Educativas no Contexto da Formação e da Educação em Serviço}

É nítida a formação pedagógica incipiente, no contexto desse Curso, e o predomínio da lógica da educação continuada nos serviços, campos de estágio. O egresso reproduz o ensino tradicional Que se mostra a ele como modelo no contexto da formação e da educação em serviço, apresentando dificuldades para a análise crítica e problematizadora da realidade.

A organização curricular por disciplinas adotada pelo Curso de Enfermagem, caracterizando-se pela fragmentação, centrando-se nos conteúdos a serem ensinados, desvinculados do processo de trabalho, dificulta a formação do egresso crítico-reflexivo, tão enfocado no projeto político pedagógico desse curso.

A maioria das escolas de enfermagem possui em sua estrutura curricular dicotomia entre o ciclo básico e o profissionalizante, com predomínio da teoria sobre a prática. Dessa forma, as experiências ligadas ao exercício da profissão são contempladas ao término do curso, no estágio curricular ${ }^{(5)}$.

Nos currículos organizados por disciplinas, conforme referencia essa autora, as mesmas se mostram isoladas e estaneues, sendo classificadas em disciplinas cientificas Que acontecem no ciclo básico, e disciplinas aplicadas pertencentes ao ciclo profissional. Nessa estrutura, espera-se Que os alunos dominem a teoria de forma abstrata e que ainda sejam capazes de aplicá-la eficazmente à realidade ${ }^{(5)}$.

A autora destaca como outra característica desse currículo tradicional, a integração-ensino-serviço, como forma de articulação teórico-prática, todavia essa acaba se constituindo em um "slogan vazio", ou seja, o trabalho, o ensino e a comunidade se constituem 
em espaços vazios e não há contextualização dos problemas de saúde na realidade dos serviços ${ }^{(5)}$.

É necessário Que a universidade busque a diversificação de cenários de ensino e aprendizagem em um conceito amplo, não somente referindo-se ao local onde se realizam as práticas, mas aos sujeitos envolvidos, à natureza e ao conteúdo das práticas desenvolvidas ${ }^{(6)}$.

Podemos perceber Que o egresso não teve bases pedagógicas consistentes para desenvolver a atividade educativa. Tal situação revela o Quanto é frágil o processo de formação desse curso no Que se refere à prática educativa, pois o egresso mostrou não dar conta de assumir uma postura reflexiva e ampliada da realidade na Qual está inserido para, a partir daí, desenvolver atividade educativa.

Cabe ressaltar a necessidade urgente de rever, no Que se refere ao conhecimento pedagógico, também os conteúdos ministrados, as estratégias pedagógicas utilizadas e a articulação teórico e prática, no sentido de problematizar as práticas educativas realizadas nos serviços de saúde, tendo em vista, inclusive, a atual política de educação permanente em saúde.

Apesar do projeto político-pedagógico do curso explicitar em sua redação uma proposta pedagógica de tornar o aluno crítico, criativo, reflexivo, como indicam as diretrizes curriculares, destacamos que, enfocar a atividade educativa, mesmo sendo apenas um recorte da formação, foco deste estudo, possibilitou nos refletir sobre a ação do docente em suas práticas pedagógicas. Nessa ótica, é preciso repensar a sua atividade no sentido de desenvolver consciência crítica, dando ênfase para a construção reflexiva, ao longo do processo formativo ${ }^{(7)}$.

Isso envolve também a formação continuada dos docentes, a revisão do projeto político pedagógico de modo coletivo e ampliado, contemplando também a revisão da articulação ensino-serviço, o Que pode ser viabilizado pela participação efetiva da universidade no Pólo de Educação Permanente em Saúde Que está em processo de construção.

Levando-se em conta, então, o processo formativo e as atividades educativas em serviço, os egressos não diferenciam educação e treinamento. Reproduzem ações educativas pontuais, mantendo o trabalho já estruturado no serviço de saúde.

A prática educativa se constitui como um "fazer educativo", e este promove mudanças, transformações de uma realidade atual para outra desejada ${ }^{(8)}$.

lá o termo treinamento, diz respeito à adaptação do homem ao serviço, não possibilitando o envolvimento genuíno com seu trabalho, nem o desenvolvimento de sua criatividade, elementos essenciais para provocar mudanças significativas ${ }^{(9)}$.

A lógica de educação nos serviços de saúde está pautada mais no desenvolvimento técnico e científico, com pouca ênfase no desenvolvimento de ação reflexiva e crítica relacionada ao processo de trabalho, não sendo geradas mudanças significativas, mesmo porQue não é incorporada a dimensão da gestão e do controle social. Ou seja, há muito a ser realizado para Que se constitua uma prática de educação permanente.

É importante discutir educação permanente e educação continuada, pois ambas assumem papéis expressivos frente às demandas necessárias de capacitação dos profissionais de saúde, em virtude dos despreparos de sua maioria ${ }^{(10)}$.

Afirma ainda Que, mesmo sendo imprescindível a educação continuada na capacitação dos profissionais de saúde, muitas vezes, seus programas estão centrados na organização de palestras, cursos, com ênfase no aperfeiçoamento técnico, sem considerar a realidade cotidiana de sua prática profissional, a resolução dos problemas Que vão surgindo, a reflexão sobre o Que faz e porque está fazendo, o Que limita a visão integrada da assistência a ser prestada ao paciente $^{(10)}$.

A educação permanente tem como lógica uma prática descentralizadora, ascendente e transdisciplinar, a Qual essa abordagem pode propiciar a democratização institucional; o desenvolvimento da capacidade de aprendizagem; da capacidade de docência e de enfrentar situações de saúde com criatividade; de trabalhar com equipes matriciais e de melhorar a Qualidade do cuidado em saúde, além de constituir práticas técnicas críticas, éticas e humanísticas ${ }^{(1)}$.

Destaca ainda, Que para expressar Qualidade e relevância social coerentes com os valores da Reforma Sanitária brasileira, é necessário Que as instituições formadoras se utilizem de meios adequados à formação de profissionais para o desenvolvimento do SUS ${ }^{(1)}$.

Além disso, a participação da população na identificação e construção de estratégias de enfrentamento dos problemas de saúde é um fator essencial para facilitar o acesso e melhorar a Qualidade dos serviços, além de permitir maior permeabilidade e compromisso das equipes profissionais relacionados aos problemas e a população sob sua responsabilidade em seu território ${ }^{(6)}$.

Do exposto até então, fica nítida a importância de investir na discussão coletiva sobre as práticas educativas no contexto da formação e dos serviços, buscando estratégias articuladas Que realmente possibilitem Que os profissionais de saúde e, especificamente, no contexto deste estudo, os enfermeiros, desenvolvam competência político-pedagógica.

\section{CONSIDERAÇÕES FINAIS}

Concluímos Que este estudo é apenas uma aproximação inicial ao tema em Questão, já Que parte de um recorte específico - as experiências de egressos de enfermagem em práticas educativas em serviços de saúde. Apesar disso, compreendemos que os significados dos egressos de enfermagem atribuídos à atividade educativa, realizada no estágio curricular supervisionado, trazem elementos Que podem contribuir para a reflexão acerca da formação pedagógica de enfermeiros nessa Universidade, bem como sobre as práticas educativas nos serviços de saúde utilizados como campo de experiências práticas, trazendo contribuição, inclusive, para a constituição do Pólo de Educação Permanente da região.

\section{REFERÊNCIAS}

1. Ministério da Saúde (BR). Portaria no 198/GM/MS de 13 de fevereiro de 2004. Institui a Política Nacional de Educação
Permanente em Saúde como estratégia do Sistema Único de Saúde para a formação e o desenvolvimento de trabalhadores 
para o setor e dá outras providências. Brasília: Ministério da Saúde; 2004.

2. Baduy RS. A formação profissional e a educação permanente em saúde. Jornal da ABEn 2002; 5.

3. Ministério da Educação e Cultura (BR). Conselho Nacional de Educação. Câmara de Educação Superior. Resolução CCNE/ CES, $n^{\circ} 3$, de 7 de novembro de 200I. Institui as Diretrizes Curriculares Nacionais do Curso de Graduação em Enfermagem. Diário Oficial da União 2001 nov 9; 1: 37.

4. Bogdan R, Biklen S. Investigação Qualitativa em educação: uma introdução à teoria e aos métodos. Porto: Porto Editora; 1994.

5. Romano RAT. Da reforma curricular à construção de uma nova práxis pedagógica: a experiência da construção coletiva de um

6. currículo integrado [dissertação]. Rio de Janeiro (RJ): Universidade Federal do Rio de Janeiro; 1999.

7. Martin GB. Parceria entre universidades e serviços: construção de um novo compromisso na formação e desenvolvimento de profissionais de saúde. Olho Mágico 2002; 9 (1): 54-8.

8. Universidade Norte do Paraná. Projeto pedagógico do Curso de Enfermagem da Unopar. Londrina: Universidade do Norte do Paraná; 2004.

9. Motta III. Educação permanente em saúde: da política do consenso à construção do dissenso [dissertação]. Rio de Janeiro (RI): Universidade Federal do Rio de Janeiro; 1998.

10. Corrêa AK, Valle ERM. O treinamento de recursos humanos em enfermagem: discurso da literatura. Rev Enferm UERJ 2000; 8 (I): 15-21.

11. Almeida MI. Educação permanente em saúde: um compromisso inadiável. Olho Mágico 1997;5 (esp).

12. Ceccim RB, Feurwerker LCM. O Quadrilátero da formação para a área da saúde: ensino, gestão, atenção e controle social. Rev Saúde Coletiva 2004; 14 (1): 41-65. 